\title{
Knowledge and beliefs regarding menstruation among Saudi nursing students
}

\author{
Najwa Karout * \\ Ibn Sina National College for Medical Sciences, Jeddah, Saudi Arabia
}

Received: August 23, 2015

Accepted: September 23, $2015 \quad$ Online Published: September 29, 2015

DOI: $10.5430 /$ jnep.v6n1p23

URL: http://dx.doi.org/10.5430/jnep.v6n1p23

\begin{abstract}
This study was undertaken to assess the knowledge and beliefs of Saudi female nursing students towards menstruation. A cross sectional survey was conducted on a sample of 400 students, the data was collected using a self-administered questionnaire. The results revealed that a considerable percentage lacked the knowledge and correct beliefs regarding menstruation. Furthermore a significant relationship was found between the marital status, academic year and the score of knowledge and beliefs but not with age. Although the source of information among the majority of the participants was derived from their mother, those who had good knowledge were the participants who belonged to the above 3rd academic year. In conclusion, it is essential to emphasize the importance of compulsory reproductive health education from an early age to help adolescent girls manage menstrual symptoms and increase their awareness; this could be achieved by adding a course of reproductive health course beginning at the intermediate school level.
\end{abstract}

Key Words: Menstruation, Knowledge, Beliefs, Saudi girls

\section{INTRODUCTION}

The menstrual cycle in females is an indicator of changes occurring during the adolescent stage. The menstrual cycle is a component of natural changes that occur in the uterus and ovaries as an essential part of sexual reproduction and it is accompanied by a change in the physical, psychological and social aspects of a woman's life. Menarche, the first onset of menstruation occurs between the ages of 11 and 15 years old with an average age of 13 years old. ${ }^{[1]}$ Girls at the age of puberty need to have educational sessions about the changes occurring to their bodies as well as inclusion of their mothers in this process so that mothers can provide healthy advice to their daughters about menstruation. ${ }^{[2]}$ The topic of menstruation still remains taboo in many countries and discussions of problems related to menstruation are treated as shameful. The attitude and behavior towards menstruation among girls is influenced by her socio-economic, cultural and religious background and moreover her knowledge about menstruation. ${ }^{[3]}$

The lack of proper knowledge about menstruation leads to negative attitude and misconceptions about this natural physiological process and may have adverse health effects. ${ }^{[4]}$ Having menstrual dysfunction is common among students and previous studies highlighted the importance of health education for early detection of these problems such as menstrual cycle irregularities, hyper- or hypomenorrhoea, polyor Oligomenorrehoa, dysmenorrhea, and premenstrual syndrome (PMS). ${ }^{[5]}$

According to some studies, girls' poor personal hygiene and unsafe sanitary conditions contribute to gynecological problems and often result in repeated cases of vulvar or pelvic infections in adolescent girls. ${ }^{[1,2]}$ Many women experience reproductive tract infections which can be trans-

*Correspondence: Najwa Karout; Email: Nkkarout@yahoo.com; Address: Ibn Sina National College for Medical Sciences, Jeddah, Saudi Arabia. 
mitted to the offspring during pregnancy. It is important to note that women with better knowledge are at less risk of these infections, therefore imparting menstrual knowledge before menarche may reduce reproductive infections of many women in the entire world. ${ }^{[4]}$

Previous studies conducted assessing knowledge about menstruation among adolescent girls throughout the world in different regions obtained varied results. Reports from the East Mediterranean region show that girls learn about menstruation only when they begin the first period. ${ }^{[6]}$ In a Jordanian study the results indicated that $82.4 \%$ of responders lacked knowledge of pre-menarcheal menstruation and this contributed to unhealthy practices during menstruation. ${ }^{[7]}$ According to Egyptian study $85 \%$ of girls had satisfactory knowledge about menstruation. ${ }^{[8]}$

A comparative study conducted in Saudi Arabia reported that $53.4 \%$ of girls in government schools and $67.9 \%$ in private schools have knowledge of menstruation. Mothers were reported to be the most common source of information in many studies ${ }^{[9,10]}$ followed by friends $(35.3 \%)$ and teachers or matrons. ${ }^{[4,10]}$ Although mothers and teachers provide information about the facts of menstruation however, they often failed to prepare the girls emotionally as the older women themselves have limited knowledge about this physiological process. Moreover the mother's educational level and socio economic background are other determinants to providing menstruation knowledge to their daughters. ${ }^{[4,11,12]}$

The results of a study conducted in Riyadh, Saudi Arabia about menstruation knowledge among adolescent demonstrated that the scores for knowledge were low and mothers, religious books and sisters were the main sources of menstruation information. Also two thirds of the girls avoided eating certain foods, drinks and activities including showering, performing perineal care and practicing several indigenous rituals during their periods. ${ }^{[13]}$

Also in another study conducted in Riyadh in secondary schools about menstruation, the results indicated a lack of knowledge among participants, ${ }^{[14]}$ while another study conducted in Al-Khobar revealed a high rate of unhealthy practices including self-administration of medication during menstruation. ${ }^{[15]}$

Recently a study conducted in Hail university in Saudi, the results show $54 \%$ overall reproductive health knowledge and found relationship with marital status and age also the study conclude the importance of health education for future generation. ${ }^{[16]}$

Results of previous studies conducted in Jordan and India about menstrual beliefs among adolescent girls indicated that discussing menstrual problems even among the closest family members does not exist, ${ }^{[17,18]}$ also talking about menstruation is considered shameful and embarrassing. ${ }^{[19]}$ The negative attitude and confusions are a result of lack of educational resources. ${ }^{[18]}$

Many folk beliefs are prevailing all over the world regarding menstruation and those beliefs are associated with many social and cultural implications. ${ }^{[2]}$ Studies in many different parts of the world and cultures reported the existence of different beliefs, for example, changes in diet, bathing, social mobility and prohibition from participating in religious activities. Bathing is considered as unhealthy and the cause of either prolonged or no bleeding by many women in Egypt. ${ }^{[8]}$

In India $50 \%$ of the women do not take shower during menstruation as they believe it will increase the intensity of pain and results in discontinuation of menstrual bleeding. Certain foods like eggs, dry fruits, and yoghurt and green leafy vegetables are avoided as these foods are considered too hot or too cold. ${ }^{[20]}$

A study from Lebanon about menstrual beliefs reported that $89.5 \%$ are restricted from social life, $24 \%$ do not remove the unwanted hair (depilation), $35.5 \%$ will alter the eating habits, $22 \%$ do not drink cold water, $20 \%$ believe amenorrhea can be prevented by avoiding Vitamin C, 20\% do not touch plants or baby and $19 \%$ would not walk barefooted. ${ }^{[21]}$ These results are consistent with the results reported from India where girls are restricted from family functions and social ceremonies, and Saudi Arabia where girls avoid Vitamin $\mathrm{C}$ and also alter their eating habits. ${ }^{[9,13,21]}$

Many studies about menstrual knowledge were conducted and practiced all around the world, but only a few related to this subject were conducted in Saudi Arabia. The studies carried out in Saudi were at the school level, and only one was carried out recently among medical students at Hail University. Therefore, the purpose of this study is to assess menstrual knowledge and beliefs among Saudi nursing students, and also to find the relationship between their level of menstrual knowledge and some of their demographic data.

\section{Methodology}

\subsection{Study design and sample}

A cross sectional survey was conducted, in nursing college in Al Khobar city at Eastern province in Saudi, all $400 \mathrm{fe}$ male students registered in the academic year 2013-2014 in all academic years were included in the study as a sample. These students represent the adolescents Saudi girls from Eastern province in Saudi; this sample size was adequate as previous studies used the appropriate size. 


\subsection{Data collection}

The data was collected using a valid, self-administered, anonymous questionnaire, included demographic data, knowledge and beliefs questions about menstruation, all the questions were close ended. The content validity was achieved by reviewing the previous similar studies.

\subsection{Ethical issues}

Data were collected after getting approval from the research ethical committee of the college, also approval of the college authorities and according to the students' academic schedule 400 questionnaires distributed to the students in their class. The questionnaires were delivered and took about 30 minutes to be completed. The purpose and the objectives of the study were explained by the researcher and students were informed that participation is not obligatory. Also the students were given an informed consent attached to the questionnaire and asked to sign it in order to assure their acceptance participating in the study, it was including that all data collected will be strictly confidential.

\subsection{Data analysis}

The collected data from the filled questionnaire were analyzed using SPSS version 16. Data were revised, coded and tabulated using the frequency and percentage. Chi square test used to test the significance of the variables with $p<.05$.
Scoring system used for assessing the student's knowledge and beliefs towards menstruation, the knowledge and beliefs section consists of 14 questions and the correct answers were pre- determined from the literature. A score of 1 were given to the correct answer and 0 for the wrong and don't know answer. Total score was obtained for each student (0-14). The total score was categorized as follows:

- Good knowledge $=$ Score $\geq 10.5(\geq 75 \%$ correct answers)

- Acceptable knowledge = Score 7-10

- Poor knowledge $=$ Score $\leq 7$.

\section{RESULTS}

The responding rate was $85.5 \%$.

\subsection{Demographic data of the participant}

The results in Table 1 showed that the majority of the students were between $18-20$ years old $(53.5 \%)$ and $81 \%$ were single; according to academic level, $39.2 \%$ were in foundation, the rest were in different academic levels also the majority of them the mothers' level of education was intermediate $(39.5 \%)$ but also $26.9 \%$ have secondary level and $13.7 \%$ the mother cannot read and write also $19.9 \%$ of them the level of mother education was university .

Table 1. Background characteristics of the sample of the students $(n=342)$ and relationship with score of knowledge and beliefs

\begin{tabular}{|c|c|c|c|c|}
\hline \multirow{2}{*}{ Variable } & \multirow{2}{*}{$\mathbf{N}$} & \multirow{2}{*}{$\%$} & \multicolumn{2}{|c|}{ Knowledge and beliefs score } \\
\hline & & & $\chi^{2}$ & $P$ value \\
\hline Age & & & 0.21 & \\
\hline$<18$ & 23 & 6.7 & & \\
\hline $18-20$ & 183 & 53.5 & & .8 \\
\hline $21-23$ & 114 & 33.3 & & \\
\hline$>23$ & 22 & 6.5 & & \\
\hline Marital status & & & 11.17 & \\
\hline Single & 277 & 81.0 & & .00 \\
\hline Married & 65 & 19.0 & & \\
\hline Academic year & & & 7.08 & \\
\hline Foundation-3rd Year & 275 & 80.4 & & .02 \\
\hline > Third Year & 67 & 19.7 & & \\
\hline Mother education & & & 8.74 & \\
\hline$<$ Intermediate & 182 & 52.9 & & .18 \\
\hline$>$ Intermediate & 160 & 46.5 & & \\
\hline
\end{tabular}

\subsection{Knowledge and beliefs about menstruation}

The results of the study showed that $45.1 \%$ of the students had acceptable knowledge and belief about menstruation, and respectively $30.2 \%, 24.1 \%$ had poor and good (see Table 2). 
According to the source of menstrual knowledge, the results showed that $58.8 \%$ of the participants received menstrual information from their mothers, $20.5 \%$ from friends, $14.9 \%$ from school teachers, and $5.8 \%$ did not receive any information (see Table 3).

Table 2. Knowledge and belief's score of the students $(n=$ 342)

\begin{tabular}{lll}
\hline Knowledge and Belief & Frequency (n) & Percent (\%) \\
\hline Poor & 104 & 30.2 \\
Acceptable & 155 & 45.1 \\
Good & 83 & 24.1 \\
\hline
\end{tabular}

Table 3. Source of knowledge about menstruation among the sample $(\mathrm{n}=342)$

\begin{tabular}{lcl}
\hline Variable & Frequency (n) & Percent (\%) \\
\hline \multicolumn{2}{l}{ Information about Menstruation received from } \\
Mother & 201 & 58.8 \\
Friend & 70 & 20.5 \\
School teacher & 51 & 14.9 \\
Don't receive any & 16 & 5.8 \\
\hline
\end{tabular}

The results about the knowledge and beliefs about menstruation were showed in Table 4. According to the question about the menarcheal age in Saudi, $16.1 \%$ answered less than 10 years old and $2.0 \%$ more than 14 , also about the menstruation duration, $1.8 \%$ answered less than 3 days, $1.8 \%$ more than 10 days and $0.6 \%$ do not know the answer, according to the menstruation frequency $10.2 \%$ of the participants answered between 10-20 days, $13.2 \%$ between $30-40$ days and $13.2 \%$ do not know, related to the normal number of pads daily used during menstruation, 5.6\% answered 1-2 pads and $16.7 \%$ more than 5 pads.

Concerning their beliefs about menstruation, $45.6 \%$ think that no need for consultation for severe dysmenorrhea, and $13.2 \%$ do not know also $19.6 \%$ perceive that no relationship between irregular menstruation and organic diseases, and $28.9 \%$ do not know.

In addition, $26 \%$ of the participants believe that the amount of blood during menstruation does not affect the women's health and $18.1 \%$ do not know, $83.0 \%$ of the participants believe also that the blood of menstruation is dirty and bleeding is useful and good to release this dirty from body, also $54.7 \%$ of the participants trust on the benefits about some kind of food omission during menstruation, and $21.9 \%$ believe that during menstruation no warm shower should be taken.

In addition to that $45.0 \%$ assume that exercise should be stopped during normal menstruation and $12 \%$ they do not know, $87.7 \%$ believe that regular menstruation means healthy female and $4.7 \%$ do not believe, and $7 \%$ do not know about that, also a significant percentage of the students assume that no relationship between having extra body hair and irregular menstruation and thyroid disorders and menstrual disorders.

\subsection{Relationship between menstrual knowledge and be- liefs score (KB) with some factors}

The results showed a relationship between academic year and marital status with the score of $\mathrm{KB}(p<.00)$ and $(p<.02)$ respectively. The results showed no relationship between $\mathrm{KB}$ scores, and age or mother level of education (see Table 1).

\section{Discussion}

The body of knowledge surrounding women's menstrual cycle remains tainted by age-old myths and taboos. Saudi females like other adolescents girls often lack knowledge regarding reproductive health, including menstrual hygiene, which can be due to socio-cultural barriers and restrictions in which they grow up, as few studies conducted in Saudi show.

Despite the number of the studies conducted about menstruation among adolescents, in Middle East and especially in Saudi Arabia, the need for highlighting this subject is an essential and necessary requirement. Majority of the girls in Saudi Arabia lack scientific knowledge about menstruation and puberty. Adolescent girls are often reluctant to discuss this topic with their parents and often hesitate to seek help regarding their menstrual problems. ${ }^{[10]}$

In the present study, the results highlighted that only $24.1 \%$ of participants had good scores regarding menstrual knowledge and beliefs. Furthermore, $30.2 \%$ and $45.1 \%$ had poor and acceptable scores respectively, while $43.8 \%$ of Saudi girls in Taiif were below the standard level of menstrual knowledge. ${ }^{[22]}$

In this study, the source of information among $58.8 \%$ was their mothers which correlates with studies conducted in Iran $55 \%{ }^{[23]}$ and India $54 \%{ }^{[10]}$ but not with those in Lebanon $86.9 \% .{ }^{[21]}$ In addition, $20.5 \%$ received menstrual information from friends, $14.9 \%$ from teachers; and $4.7 \%$ did not receive any.

These results indicate a lack of knowledge and beliefs about menstruation whatever their source of information. As shown in many previous studies, ${ }^{[2,7,21,23]}$ the information and beliefs towards menstruation are transferring from generation to generation by mothers, no matter what the educational level of participants were.

The results of the current study showed that the majority of participants knew the normal menarcheal age, and this may be due to the majority of them having had a normal onset of menarche. Such result $(79.2 \%)$ is more than the finding of a previous study in Saudi (65\%), ${ }^{[24]}$ and in Egypt (48\%). ${ }^{[25]}$ 
Table 4. Knowledge and belief's questions distribution of the sample of the students $(n=342)$

\begin{tabular}{|c|c|c|}
\hline Variable & Frequency (n) & Percent (\%) \\
\hline \multicolumn{3}{|c|}{ Normal Menstruation should be started } \\
\hline Less than 10 years & 55 & 16.1 \\
\hline $11-14$ & 271 & 79.2 \\
\hline More than 14 & 7 & 2.0 \\
\hline \multicolumn{3}{|c|}{ Normal Menstruation lasts for (days) } \\
\hline Less than 3 & 6 & 1.8 \\
\hline $3-7$ & 246 & 71.9 \\
\hline More than 7 & 87 & 25.5 \\
\hline Don't know & 2 & 0.6 \\
\hline \multicolumn{3}{|c|}{ Regular menstruation repeated each } \\
\hline 10-20 days & 35 & 10.2 \\
\hline 20-30 days & 213 & 62.3 \\
\hline 30-40 days & 45 & 13.2 \\
\hline Don’t know & 45 & 13.2 \\
\hline \multicolumn{3}{|c|}{ Normal number of pads during menstruation } \\
\hline 1-2 pads & 19 & 5.6 \\
\hline 3-5 pads & 260 & 76.0 \\
\hline More than 5 pads & 57 & 16.7 \\
\hline \multicolumn{3}{|c|}{ Severe pain during Menstruation need physician consultation } \\
\hline Yes & 139 & 40.6 \\
\hline No & 156 & 45.6 \\
\hline Don’t know & 45 & 13.2 \\
\hline \multicolumn{3}{|c|}{ Irregular menstruation may due to organic disease } \\
\hline Yes & 173 & 50.6 \\
\hline No & 67 & 19.6 \\
\hline Don’t know & 99 & 28.9 \\
\hline \multicolumn{3}{|c|}{ The amount of blood menstruation affect health } \\
\hline Yes & 189 & 55.3 \\
\hline No & 89 & 26.0 \\
\hline Don’t know & 62 & 18.1 \\
\hline \multicolumn{3}{|c|}{ The blood of menstruation is dirty and should be release from body } \\
\hline Yes & 284 & 83.0 \\
\hline No & 39 & 11.4 \\
\hline Don’t know & 17 & 5.0 \\
\hline \multicolumn{3}{|c|}{ Any omission of food or drink during menstruation } \\
\hline Yes & 187 & 54.7 \\
\hline No & 118 & 34.5 \\
\hline Don’t know & 34 & 9.9 \\
\hline \multicolumn{3}{|c|}{ Have a warm shower during menstruation } \\
\hline Yes & 235 & 68.7 \\
\hline No & 75 & 21.9 \\
\hline Don’t know & 30 & 8.8 \\
\hline \multicolumn{3}{|c|}{ Do exercise during menstruation } \\
\hline Yes & 141 & 41.2 \\
\hline No & 154 & 45.0 \\
\hline Don’t know & 41 & 12.0 \\
\hline \multicolumn{3}{|c|}{ Having regular monthly menstruation is a healthy sign } \\
\hline Yes & 300 & 87.7 \\
\hline No & 16 & 4.7 \\
\hline Don’t know & 24 & 7.0 \\
\hline \multicolumn{3}{|c|}{ Having extra body hair distribution may relate to menstrual dysfunctions } \\
\hline Yes & 131 & 38.3 \\
\hline No & 80 & 23.4 \\
\hline Don’t know & 129 & 37.7 \\
\hline \multicolumn{3}{|c|}{ Thyroid gland dysfunction cause menstruation disorders } \\
\hline Yes & 150 & 43.9 \\
\hline No & 28 & 8.2 \\
\hline Don’t know & 161 & 47.1 \\
\hline
\end{tabular}


In addition, the majority of participants knew the normal duration and frequency of menstruation. Furthermore, the results indicated that the participants in our study were more knowledgeable than those in another previous study conducted in Nigeria, whereby $10 \%$ and $38 \%$ knew the normal frequency and duration of menstruation respectively, ${ }^{[26]}$ and $21.6 \%$ of Saudi girls. ${ }^{[27]}$

Singh Amit in India found in a prior study that $43 \%$ of their participants perceived their menstruation as a good thing for health, and $77.5 \%$ perceived the blood of menstruation as dirty. This is similar to our findings $(83 \%)$ in the current study. Also, in Amit's study, $84 \%$ of the participants avoided certain foods ${ }^{[28]}$ whereas $64.7 \%$ has the same beliefs in our study.

In Esawi's study about menstrual knowledge and attitude in Egypt; it was found that $50 \%$ of participants perceived that they should seek medical advice during severe bleeding and $21 \%$ during dysmenorrhea, ${ }^{[25]}$ also it's found in another study among Jordanian girls that $37.7 \%$ of the participants believed in using analgesia during dysmenorrhea. ${ }^{[29]}$ In the current study, the percentage was similar (55.3\%).

Previous studies conducted about perception towards menstruation, $42.6 \%$ of the participants in an earlier study avoided certain foods and drinks such as milk and spicy foods, in addition, $88.8 \%$ took baths during menstruation. ${ }^{[30]}$

In addition, a study conducted about menstrual knowledge and beliefs among Lebanese adolescents show that $35.5 \%$ changed their food habit, $22 \%$ omitted cold drinks. ${ }^{[21]}$ In a Saudi study $50 \%$ of the participants had many restrictions regarding food, drink and activities. ${ }^{[27]}$ These results are relevant to our current study wherein $64.4 \%$ thought that they should omit some food and drinks.

In the Lebanese study, $66.9 \%$ of the participants did not take shower during the first three days of menstruation, and $16.5 \%$ did not take showers at all during menstruation ${ }^{[21]}$ in Saudi study, $71.7 \%$ of Saudi girls did not take showers during the first 3 days of menstruation. ${ }^{[27]}$ In our study $30.7 \%$ did not believe in taking warm showers during menstruation.

Furthermore, in the Saudi study $44 \%$ of nursing students do not perform exercise during menstruation. Whereas $70.3 \%$ of the participants of the Lebanese study do not practice any activities during menstruation. ${ }^{[21]}$ In the current study $57 \%$ believed that no exercise should be performed during menstruation.

These results are crucial in showing how everyday life eventssuch as, daily activity, consuming any kind of food, taking showers, attending college, and participating in social activities-are interrupted by menstruation so preventing the interruption of everyday life events by menstruation is important for female health and well-being development. ${ }^{[16]}$

In addition to the mentioned results related to the daily life events of the students, in our study despite that the students supposed to know the function of hormones during their first year nursing study, the results showed that $60.4 \%$ of the nursing students do not know that having extra body hair distribution may relate to menstrual dysfunctions and $55.3 \%$ do not know that thyroid gland dysfunction may cause menstrual disorders. So it should be emphasis on the effect of hormones on menstrual disorders in first year of nursing curriculum as it will help on understanding the normal function of menstruation. Having knowledge about any subject relating to menstruation could help in the early diagnosis of any physical dysfunction. ${ }^{[22]}$

The results in our study also show that nursing student's knowledge and beliefs about menstruation could be alarming for decision makers with regards to reproductive health. However, the results should emphasize female menstrual hygiene and nutritional issues in order to prevent any pelvic infections occurring due to insufficient knowledge of menstruation. It is expected to empower the adolescents to delineate between physiologic and abnormal uterine bleeding. ${ }^{\text {[24] }}$

The findings in the previous study showed that after health education, participants in Bangladesh reported a significant improvement in "high knowledge and beliefs" scores also in overall good menstrual practices they also reported a significant improvements in the regularity of their menstrual cycle and fewer complications during menstruation. These results demonstrate the feasibility of implementing a health education program for the adolescents. ${ }^{[30]}$

In the current study, a significant relationship between the knowledge and beliefs (KB) score and marital status is similar to Hail results. ${ }^{[16]}$ This appears normal because being married; the girls tend to increase their awareness towards the physiology of the reproductive system to prepare them for future pregnancy. However, unlike previous studies, ${ }^{[16,30]}$ this study did not find any relationship between age and KB score which may be because there was no significant age variation. In addition, a significant relationship between the $\mathrm{KB}$ score and academic year was highlighted in this study as participants belonged to two educational levels; those who passed a reproductive health course and those who did not.

\section{Conclusion}

The results of this study indicate that as a whole, the girls in Eastern Province of Saudi Arabia were unaware of the information relating to menstruation. This included the im- 
portance of increasing awareness and giving accurate information using scientific sources, such as schools, colleges or health team members. It is required to discuss the issue related to menstruation early in the physiology of the hormones course to be easy to understand during the course of reproductive health

Other sources such as media outlets may be used to increase awareness amongst mothers in the community. This may aid in preventing any future physical problems, increasing self-confidence, and improving the quality of life.

\section{ACKNOWLEDGeMENTS}

The authors show gratitude to all the participants, also appreciate Mrs. Sara jabeen and Mrs. Soumia Ponan for their help. A special thanks to Ms. Iman Ahmed, Ms. Iman Mohamed from English department of Ibn Sina college for their support and help in reviewing and editing the article.

\section{CONFLicts OF INTEREST Disclosure}

The author declares that there is no conflict of interest.

\section{REFERENCES}

[1] Bhatia J, Cleland J. Self-reported symptoms of gynecological morbidity and their treatment in south India. Studies in Family Planning. 1995; 26(4): 203-216. PMid:7482678 http://dx.doi.org/10.23 07/2137846

[2] Ali TS, Rizvi SN. Menstrual knowledge and practices of female adolescents in urban Karachi, Pakistan. Journal of Adolescence. 2010; 33(4): 531-541. PMid:19589587 http://dx.doi.org/10.1016 $/ \mathrm{j}$.adolescence. 2009.05.013

[3] Adrijadutta, Nirmalaya M, et al. Menstruation and menstrual hygiene among adolescent girls of West Bengal, India: A school based comparative study. GJMEDPH. 2012; (5): 50-57.

[4] Dasgupta A, Sarkar M. Menstrual Hygiene: How Hygienic is the Adolescent Girl? Indian J Community Med. 2008; 33(2): 77-80. PMid:19967028 http://dx.doi.org/10.4103/0970-0218.40 872

[5] Karout N, et al. Prevalence and pattern of menstrual disorders among Lebanese nursing students. EMHJ. 2012; 18(4).

[6] Omran A, Al Hafez G. Health education for adolescent girls.WHO Regional Office for the Eastern Mediterranean. 2006. Available from: http://www. emro.who.int/dsaf/dsa722.pdf

[7] Jarrahss, Kamel AA. Attitudes and practices of school-aged girls towards menstruation. International Journal of Nursing Practice. 2012; 18: 308-305. PMid:22621303 http://dx.doi.org/10.1111/j $.1440-172 \mathrm{X} .2012 .02032 \cdot \mathrm{x}$

[8] El-Shazly MK, Hassane, et al. Knowledge about menstruation and practices of nursing students affiliated to university of Alexandria. Journal of the Egyptian Public Health Association. 1990; 65(5-6): 509-523. PMid:2134088

[9] Dhingra R, Kumar A, Kour M. Knowledge and Practices Related to Menstruation among Tribal (Gujjar) Adolescent Girls. Ethno-Med. 2009; 3(1): 43-8.

[10] Omidvar S, Begum K. Factors influencing hygienic practices during menses among girls from south India- A cross sectional study. International Journal of Collaborative Research on Internal Medicine \& Public Health. 2010 Dec; 2(12): 411-23.

[11] Marvan M, Cortes-Iniestra S, Gonzalez R. Beliefs about and attitudes toward menstruation among young and middleaged Mexicans. Sex Roles. 2005; 53: 273-279. http://dx.doi.org/10.1007/s1119 9-005-5685-3

[12] Khanna A, Goyal R, Bhawsar R. Menstrual practices and reproductive problems: A study of adolescent girls in Rajasthan. Journal of Health Management. 2005; 7: 91-107. http://dx.doi.org/10. $1177 / 097206340400700103$
[13] Moawed S. Indigenous practices of Saudi girls in Riyadh during their menstrual period. Eastern Mediterranean Health Journal. 2001; 7: 197-203.

[14] Fetohy E. Impact of health education program for secondary school Saudi about menstruation at Riyadh city. Egypt Public Health Journal. 2007. PMid: 18217327

[15] Abalhusein N, Taha A. Knowledge and attitude of females school students on medications in eastern Saudi Arabia. Saudi Medical Journal. 2007.

[16] Rafia, Alsabhan. Study of knowledge and practice of university females regarding reproductive health and hygienw in Hail, Saudi Arabia, International journal of women's health and reproductive sciences. 2015; 3(1).

[17] UNICEF. Children in Jordan: Situation analysis 2006-2007. 2007.

[18] Cooper S, Koch P. "Nobody told me nothing", communication about menstruation among low-income African American women. Women \& Health. 2007; 46: 57-78. PMid:18032175 http://dx.doi.org /10.1300/J013v46n01_05

[19] Burrows A, Johnson S. Girls' experiences of menarche and menstruation.Journal of Reproductive and Infant Psychology. 2005; 23: 235-249. http://dx. doi.org/10.1080/02646830500165846

[20] Khan A. Adolescent and reproductive health in Pakistan: A literature review. United Nation Populations Funds and Population Council. 2000.

[21] Santina T, Wehbe N, Ziade FM, et al. Assessment of beliefs and practices relating to menstrual hygiene of adolescent girls in Lebanon. Int J Health Sci Res. 2013; 3(12): 75-88.

[22] Alosaimi J. Saudi intermediate school girls' knowledge, attitude and practices about puberty in Taif, Saudi Arabia. International Journal of Medical Science and Public Health. 2014; 3(2).

[23] Pourislami M. Assessing Knowledge, Attitudes, and Behavior of Adolescent Girls in Suburban Districts of Tehran About Dysmenorrhea and Menstrual Hygiene, Journal of International Women's Studies. 2002.

[24] Akpenpuun JR, Azende PM. Menstrual Knowledge and Practices among Adolescents Females in Makurdi Metropolis. GJISS. 3(3): 113-121.

[25] Eswi A, et al. Menstrual attitude and knowledge among Egyptian females adolescents. Journal of American Science. 2012; 8(6).

[26] Singh AK, et al. Knowledge, attitude and practices among females adolescents in Uttarakhand. PJMS. 2013; 3(2).

[27] Abdelhameed M, et al. Assessment of Dysmenorrhea and Menstrual Hygiene Practices among Adolescent Girls in Some Nursing Schools 
at EL-Minia Governorate, Egypt. Journal of American Sciences. 2011; 7(14).

[28] Shanbhag D, Shilpa R. Perceptions regarding menstruation and Practices duringmenstrual cycles among high school going adolescent girls inresource limited settings around Bangalore city, Karnataka, India. International Journal of Collaborative Research on Internal Medicine \& Public Health. 2012; 4(7).
[29] Bata SM. Age at menarche, menstrual patterns, and menstrual characteristics in Jordanian adolescent girls. International Journal of Gynecology and Obstetrics. 2012.

[30] Haque SE, Rahman M, Itsuko K, et al. The effect of a school-based educational intervention on menstrual health: an intervention study among adolescent girls in Bangladesh. BMJ. 2014. PMid:24993753 http://dx.doi.org/10.1136/bmjopen-2013-004607 